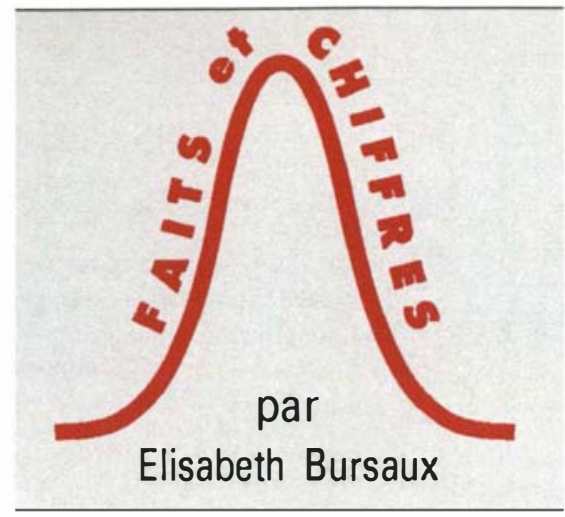

\title{
Régions critiques, l'exemple du Honduras
}

1. Kasperson JX, Kasperson RE, Turner II BL. Critical environmental regions : international perspectives. Tokyo: UN University Press, 1994 (sous presse).

2. Kirshhoff LV'. American trypanosomiasis (Chagas'disease) : a tropical disease now in the United States. $N$ Engl I Med 1993; 329: 639-44.

3. Banque Mondiale. Rapport sur le développement dans le monde en 1993. Investir dans la santé. Oxford: Oxford University Press, 1993.

4. Skole D, Tucker C. Tropical deforestation and habitat fragmentation in the Amazon. Science 1993; 260 : 1905-10.

5. W'alsh JF, Molyneux DH, Birley NH. Deforestation effects on vector-borne disease. Parasitology 1993; 106: 655-75.

6. Emorine L, Strosberg D. Interféron $\gamma$ et leishmaniose chimiorésistante. médecine/sciences 1993; 9: 1214-7.

Source: Almendares J, Sierra M, Anderson PK. Critical regions, a profile of Honduras. Lancet 1993 ; 342 : 1400-2.

$\mathrm{m} / \mathrm{s} n^{\circ} 2$ vol. 10, février 94
L

e Honduras est un petit pays montagneux tropical d'Amérique centrale qui compte 5,5 millions d'habitants (figure 1). Au cours des vingt dernières années, son paysage a été transformé par la déforestation, l'excès de pâturage, et la monoculture. Au sud du pays, les conséquences ont été dramatiques: changement dans le régime des pluies et dans la fertilité des sols, élévation de la température moyenne de $7,5^{\circ} \mathrm{C}$ (Tableau I). Le déboisement de la partie centrale et du nord du Honduras a affecté les bassins hydroliques et les disponibilités en eau; les changements climatiques et leurs conséquences ont déjà accéléré le développement des maladies transmises par les insectes. Les sols se sont amollis et les tempêtes, accompagnant les changements climatiques de ces dix dernières années, ont entraîné d'importants glissements de terrain et inondations. Le Honduras est donc devenu particulièrement vulnérable à l'instabilité climatique. Il ne constitue pas un exemple isolé : les systèmes de base qui sous-tendent la vie sont aussi menacés en Haïti, aux Philippines, dans le bassin de Mexico, le sud-est du Kenya, l'est de Bornéo, la moyenne montagne au Népal, le plateau d'Ordos en Chine, l'Amazonie et la mer d'Aral (ex-URSS) [1] !

\section{Les maladies transmises} par des vecteurs

- Le paludisme

Dans la région de Choluteca, au sud du Honduras, le paludisme a diminué : l'élévage intensif, la culture de la canne à sucre et du coton, entraînant la dessication et l'érosion des sols, ont altéré le cycle hydrologique régional. L'élévation prolongée de la température ambiante a, par ailleurs, rendu la région trop chaude pour l'anophèle. Mais cette semidésertification a chassé la population vers les villes, les grandes plantations et les sites industriels plus au nord. De grands pans de la forêt tropicale ont été coupés et les immigrants qui s'y concentrent ne sont pas immunisés contre le paludisme. L'usage immodéré des pesticides (figure 2) dans les plantations de bananes, d'ananas et de melons a rendu les anophèles résistants à la plupart des insecticides. Vingt mille cas de paludisme (Plasmodium vivax pour $98 \%$ ) étaient recensés en 1987; on en dénombre aujourd'hui 90000 , dont $85 \%$ dans le nord-est du pays (figure 3).

\section{- La maladie de Chagas}

Les trypanosomes américains sont responsables des "mégasyndromes" dans certaines régions et d'une cardiomyopathie avec arythmie qui est devenue la première cause de mort subite en milieu rural latinoaméricain [2]. Les insectes piqueurs, Rhodnius prolixis et Triatoma dimitata, en sont les principaux vecteurs, les réservoirs étant constitués par l'opossum, le rat, le chat et le chien. Les modifications de l'environnement ont eu des conséquences sur chacune des composantes du cycle de la vie: entre 1964 et 1990, 
le Honduras a perdu $34 \%$ de ses forêts de pins et de feuillus, transformés en bois de constructions civiles et militaires et en combustible. Le déboisement se poursuit au rythme d'un quart de la forêt tous les dix ans [3], et les "effets de lisière " (comme pour l'Amazonie) dus aux routes et à l'urbanisation, font plus que doubler son impact sur la diversité biologique [4]. Privés d'habitat et de nourriture, les animaux réservoirs et les insectes vecteurs des parasitoses migrent aussi vers les bidonvilles qui entourent les villes. Partout l'élévation de la température ambiante raccourcit le cycle des générations, stimule la recherche de sang, augmente le nombre de parasites actifs dans les fèces des insectes, ce qui amplifie la population des vecteurs et la transmission des parasites [5]. Sur 10601 habitants des régions endémiques pour la maladie de Chagas examinés en 1992, 23,5\% étaient séropositifs. A Tegucigalpa, capitale du Honduras, $45 \%$ des triatomes étaient infectés par Trypanosoma cru$z e i$. La transfusion sanguine est devenue une source significative de transmission de la maladie de Chagas et du paludisme.

\section{- La leishmaniose}

Les leishmanies pathogènes ont un cycle dans les phlébotomes, les rongeurs puis les chiens. L'intrusion dans les forêts du Honduras des constructeurs de routes ainsi que des réf ugiés et soldats du Salvador et du Nicaragua voisins a fortement augmenté le nombre de cas de formes graves, cutanées et viscérales, de leishmaniose [6].

\section{- La mouche blanche}

La mouche blanche de la patate douce (Bemisia tabaci) est présente au Honduras depuis de nombreuses années. Jusqu'en 1980, elle était considérée comme peu nuisible, mais, depuis 1989, elle est devenue un vecteur important de virus pour les cultures (coton, tomates, haricots). L'expansion des cultures traditionnelles et industrielles, les sécheresses de plus en plus sévères

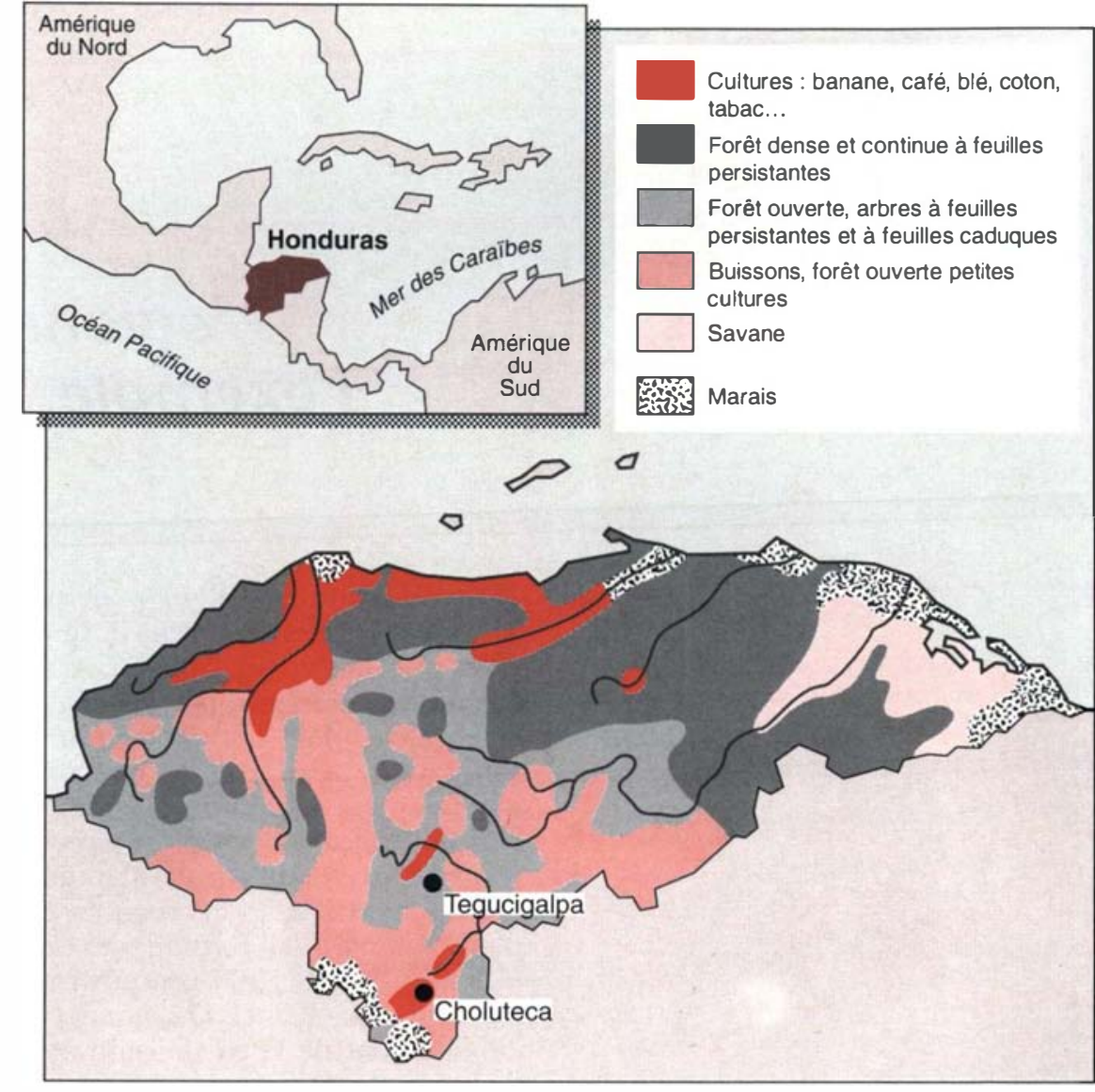

Figure 1. Honduras. Utilisation des terres. En encart: situation géographique.

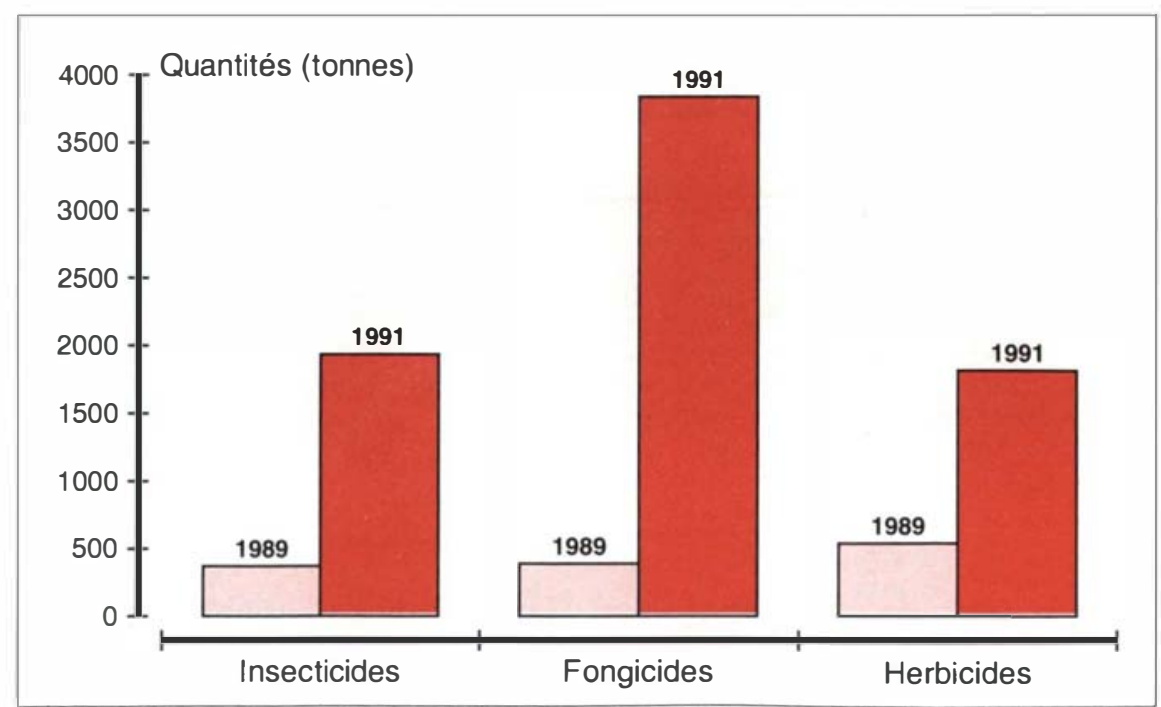

Figure 2. Importations de pesticides par le Honduras. 


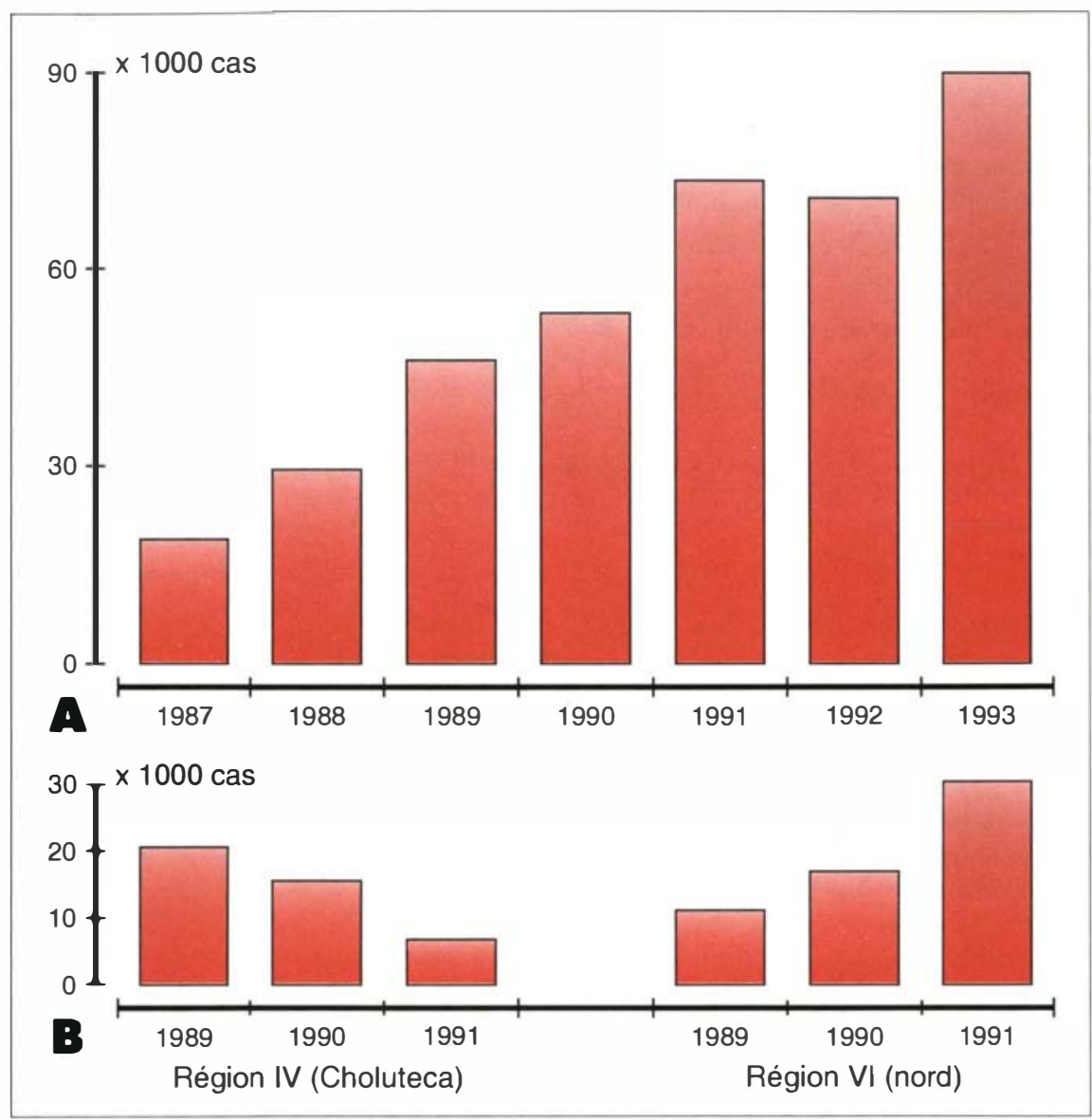

Figure 3. Cas de paludisme signalés aux autorités sanitaires. A : dans l'ensemble du Honduras, de 1987 à 1993. B : évolution du paludisme dans deux régions: Choluteca, où la température ambiante s'est accrue au point de rendre la région inhospitalière pour tous, y compris les anophèles, et où le paludisme régresse; région du Nord, où les mouvements de population ont amené des sujets non immunisés contre le paludisme, qui voit le paludisme progresser.

Tableau

TEMPÉRATURE AMBIANTE MOYENNE DE LA STATION

DE LOS ENCUENTROS, DÉPARTEMENT DE CHOLUTECA (ALTITUDE $95 \mathrm{M})$, SUD DU HONDURAS

\begin{tabular}{|cccc|}
\hline Année & Température $^{\circ} \mathbf{C}$ & Année & Température $^{\circ} \mathbf{C}$ \\
\hline 1972 & 22,64 & 1982 & 23,04 \\
1973 & 21,05 & 1983 & 25,30 \\
1974 & 19,29 & 1984 & 29,27 \\
1975 & 19,60 & 1985 & 29,73 \\
1976 & 20,01 & 1986 & 30,76 \\
1978 & 23,89 & 1987 & 30,74 \\
1979 & 23,22 & 1988 & 29,39 \\
1980 & 23,25 & 1989 & 29,62 \\
1981 & 22,65 & 1990 & 30,08 \\
\hline
\end{tabular}

$\mathrm{m} / \mathrm{s} n^{\circ} 2$ vol. 10, féurier 94 et fréquentes ont permis l'explosion de la population de mouches blanches. En 1991, $80 \%$ à $100 \%$ des plants de coton étaient infectés, avec perte complète de la récolte en maints endroits ; en 1990-1992, $70 \%$ de la récolte de tomates de la vallée de Comayagua ont été perdus; c'est $70 \%$ de la récolte de haricots qui ont été perdus en 1989-1990 à cause du bean golden mosaic geminivirus. C'est le plus grave des agents pathogènes pour les haricots d'Amérique latine tropicale. Plus de 2,5 millions d'hectares de cultures de haricots sont menacés et au moins 1 million d'hectares ne peuvent être cultivés sous peine de perdre l'intégralité de la récolte.

\section{Impact clinique}

C'est dans le haricot que réside la source principale des protéines du régime alimentaire de la population pauvre d'Amérique latine. La perte de la nourriture de base diminue encore la croissance et le développement, réduit les défenses immunitaires et favorise la dissémination des maladies transmissibles. Aujourd'hui, plus de $60 \%$ des enfants de moins de 10 ans souffrent de malnutrition (stade I et plus). Le kwashiorkor et le marasme, qu'on n'observait que chez les enfants, sont maintenant fréquents chez les tout-petits.

Autres dangers: la dengue est en augmentation dans les zones périurbaines, car les insectes Aedes prolifèrent du fait du réchauffement; la fièvre jaune réapparaît.

\section{Conclusion}

Les écosystèmes tropicaux sont, par nature, plus fragiles que les écosystèmes des pays tempérés et nordiques car ils n'orit pas eu à faire face, jusqu'à présent, à de larges variations météorologiques. Après plusieurs agressions sévères et simultanées, les écosystèmes du Honduras sont devenus extrêmement fragiles, rendant le pays de plus en plus vulnérable aux changements de condition météorologique, comme l'indiquent les modifications des populations d'insectes et des maladies infectieuses 